\title{
Pengaruh Komunikasi Antar Pribadi Orang Tua Dengan Anak dan Pengetahuan Tentang Seks Terhadap Perilaku Seks Remaja Siswa SMA Jakarta Pusat
}

\author{
Devin Saputra, Rezi Erdiansyah \\ saputra.devin1995@gmail.com,rezie@fikom.untar.ac.id
}

Fakultas Ilmu Komunikasi Universitas Tarumanagara

\begin{abstract}
This study aimed to analyze the relationship or negative influence of communication between parents and childer on sexual behavior, to find out if there is a negative influence of knowledge on sexual behavior or not, and to determine whether communication between parents and knowledge together has a negative effect on sexual behavior. This study used quantitative research. The conclusion of the study is about the negative influence of interpersonal communication are between parents and children on sexual behavior that makes children behavior negative. This means that the better communication between parents and children affect the decrease in free sex behavior, the negative influence of knowledge about sex on sexual behavior. This means that the better knowledge about sex will affect the decline in sexual behavior, and interpersonal communication between parents and children and knowledge about sex together have a negative effect on sexual behavior.
\end{abstract}

Keywords: Communication, Sex Knowledge, Sex Behavior

\begin{abstract}
Abstrak
Penelitian ini menguji variabel pengaruh komunikasi antar pribadi dengan pengetahuan tentang seks. Tujuannya untuk mengetahui apakah terdapat dampak negatif komunikasi antar pribadi orangtua dengan perilaku seks, apakah terdapat pengaruh negatif pengetahuan terhadap perilaku seks, dan untuk mengetahui apakah komunikasi antar pribadi orangtua dan pengetahuan bersama-sama berpengaruh negatif terhadap perilaku seks. Metode yang digunakan dalam penelitian ini adalah metode kuantitatif. Inti dari penelitian ini yaitu adanya pengaruh negatif komunikasi antar pribadi orangtua dengan anak terhadap perilaku seks. Artinya semakin baik komunikasi antar pribadi orangtua dengan anak maka akan berpengaruh terhadap penurunan perilaku seks bebas. Adanya pengaruh negatif pengetahuan tentang seks terhadap perilaku seks. Artinya semakin baik pengetahuan tentang seks maka akan berpengaruh terhadap penurunan perilaku seks, dan komunikasi antar pribadi orangtua dengan anak dan pengetahuan tentang seks bersama-sama berpengaruh negatif terhadap perilaku seks.
\end{abstract}

Kata Kunci: Komunikasi, Pengetahuan Seks, Perilaku Seks 


\section{Pendahuluan}

Perilaku seks merupakan sikap atau perilaku yang "sangat riskan" di kalangan remaja khususnya bagi remaja yang belum menikah, karena mereka rentan untuk melakukan perilaku seks tersebut. Perilaku seks di kalangan remaja dimulai dari level yang paling rendah dari mulai ketertarikan antar lawan sejenis, kemudian berpacaran, berpegangan tangan, dan menjurus kepada mencium pipi, kening dan mulut. Setelah itu pada masa remaja yang rentan dengan meningkatkan libido seksual, akan meningkat menjadi berpelukan, memegang buah dada, memegang alat kelamin dan melakukan senggama (Sarwono, 2012: 11). Dari hasil survei yang dilakukan oleh Sumber Kesehatan Reproduksi Remaja pada tahun 2015-2016, membuktikan bahwa remaja yang telah melakukan hubungan seksual pada usia 14-19 tahun sebesar 68,6\% dan yang berusia 20-24 tahun sebesar 95,2\%. Alasan para remaja tersebut melakukan perilaku seks pranikah adalah karena pengaruh teman dan pacar yang membujuk. Hasil penelitian seperti ini membuat orang tua lebih waspada dalam mengawasi anak ataupun berkomunikasi dengan anak terlebih masalah seksual.

Penelitian tentang hubungan komunikasi antar pribadi orangtua dengan anak dan pengetahuan tentang seks dengan perilaku seksual berisiko pada remaja belum banyak dilakukan di Indonesia. Pada penelitian ini fokus pada kota Jakarta Pusat yang merupakan salah satu kota metropolitan di Indonesia. Di kota ini, remaja terindikasi banyak melakukan perilaku seks. Oleh karena itu, sangat penting dilakukan penelitian mengenai hubungan komunikasi antar pribadi orang tua dengan anak dan pengetahuan tentang seks dengan perilaku seksual pada remaja, khususnya remaja di Jakarta Pusat.

Dari fenomena yang ada tersebut, maka penelitian ini akan menganalisis pengaruh komunikasi antarpribadi orangtua dengan anakdan pengetahuan tentang seks terhadap perilaku seks remaja siswa SMA Jakarta Pusat. Peneliti mencoba untuk mengungkap sejumlah permasalahan yakni apakah terdapat pengaruh negatif komunikasi antar pribadi orangtua dengan anak terhadap perilaku seks? apakah terdapatpengaruh negatif pengetahuan terhadapperilaku seks? apakah komunikasi antar pribadi orangtua dengan anak dan pengetahuan bersama-sama berpengaruh negatif terhadap perilaku seks?

Menurut Mulyana (2012) komunikasi interpersonal yaitu komunikasi yang dilakukan orang-orang secara tatapmuka, yang membuat setiap orang yang mengetahui reaksi orang lain secara langsung yaitu secara verbal maupun nonverbal. Komunikasi interpersonal ini adalah komunikasi dua orang seperti dua sahabat, suami istri, murid dan guru, anak dan orangtua dan lainnya. Menurut Notoatmodjo (2007), pengetahuan adalah hasil yang didapatkan atau hasil yang diketahui dari penginderaan yang dimiliki seseorang seperti penglihatan, penciuman, pendengaran dan sebagainya. Berdasarkan pengetahuan tersebut orang tua dapat berperan sebagai edukator dan motivator untuk anaknya. Orang tua yang memiliki pengetahuan baik dapat melakukan pencegahan terhadap anak secara dini dengan cara memberitahukan hal-hal yang seharusnya dia lakukan dan yangseharusnya dihindari.

Salah satu cara untuk meredam atau mengurangi perilaku seks pra nikah adalah menerapkan pendidikan seks. Diharapkan dengan menerapkan pendidikan seks yang baik akan mengurangi perilaku seks bebas dan akan berdampak pada kehamilan, dan penyakit menular seksual (PMS), dan juga depresi serta pengurangan moral buruk (Sarlito, 2014:182) dalam (Fathunaja,2013:7).

Pendidikan seks tidak hanya sekedar pembahasan mengenai pelajaran biologi manusia, tetapi juga berhubungan dengan hubungan sosial dengan sesama. Maka 
pendidikan seks adalah hal yang sangat penting khususnya bagi para remaja karena pendidikan seks yang diajarkan dengan baik akan membuat anak lebih memahami bahaya seks diluar nikah serta mendorong refleksi yang kritis tentnag pengalaman atau kehidupan pribadi yang dialami seseorang, khususnya remaja (Fathunaja,2013:7).

Sebagian besar orang memberi saran agar pendidikan seks, khususnya pada anak dimulai dari keluarga yang merupakan unit terkecil dalam kehidupan sosial. Pada masa remaja memang pendidikan seks patut mendapatkan perhatian serius karena pada masa remaja dimana libido dan hormonal meningkat, emosi meningkat, maka masa remaja adalah masa dimana orang tua menjadi paham sepenuhnya dan sulit untuk mengatur emosi dan hubungan antara anak dengan orang tua menjadi lebih sulit daripada masa kanah-kanak, karena remaja cenderung lebih tinggi dorongan dan rasa keingintahuannya serta menjadilebih mudah dipengaruhi lingkungan. Maka dari itu pendidikan seks misalnya tentang bahaya dan dampak seks bebas, bentuk anatomi dan proses reproduksi manusia menjadi hal terpenting untuk diajarkan, selain itu, juga dapat ditambah dengan teknik-teknik pencegahannya (alat kontrasepsi).

Pengetahuan remaja yang kurang akan mengetahui tentangperilaku seks pranikah, maka sangatlah mungkin apabila membuat mereka salah dalam bersikap dan kemudian mempunyai perilaku terhadap seksualitas.

Perilaku seks adalah sebuah tingkah laku yang diingini dan didorong olehhasrat seksual, adapun dengan lawan jenisnya dan dengan sesama jenis (Sarwono, 2010, h.174). Menurut Hoskins (2014), perilaku seksual adalah sebuah aktivitas fisik yang menggunakan tubuh melakukan dan mengekspresikan perasaan secara erotis atau mengeluarkan perasaan afeksi. Perilaku seksual adalah salah satu bentuk sikap yang merupakan faktor yang berhubungan dengan perilaku. Ada anggapan atau persepsi yang menyatakan bahwa adanya hormon androgenik yang meningkat pada masa pubertas untuk kedua jenis kelamin dan adanya mentalitas atau persepsi seseorang secara psikologis untuk terlibat dalam perilaku seksual, juga dimasukkan ke dalam model biososial.

\section{Metode Penelitian}

Pada penelitian ini digunakan metode penelitian kuantitatif. Alasannya adalah karena ingin menganalisis hubungan atau pengaruhantara variabel independen (bebas) dnegan variabel dependen (Y) dengan mengunakan alat analisis statistik serta untuk menguji hipotesis yangtelah ditetapkan (Sugiyono, 2017).

Pada penelitian ini yang menjadi populasi adalah para remaja yang telah melakukan perilaku seks. Menurut Sugiyono (2017:61) populasi adalah wilayah generalisasi yang terdiri atas obyek/subyek yang memiliki kuantitas dan karakteristik tertentu yang ditetapkan oleh peneliti untuk dipelajari dan kemudian ditarik kesimpulannya. Jadi populasi bukanhanya orang, tetapi juga objek dan benda-benda alam yang lain.

Sampel merupakan sebagian dari populasi yang memiliki karakteristik yang relatif sama dan dianggap dapat mewakili populasi. Teknik pengambilan sampel pad apenelitian ini adalah dengan teknik Non Probability Sampling. Teknik Non Probability sampling yang dipilih yaitu dengan accidental sampling adalah "teknik penentuan sampel berdasarkan faktor spontanitas, artinya siapa saja yang tidak sengaja bertemu dengan peneliti dan sesuai dengan karakteristik", maka orang tersebut dapat 
digunakan sebagai sampel (responden), yaitu 100 orang siswa di Mahatma Gandhi School, Gandhi Memorial School (GMIS), dan Tarsisius 1.

Tabel 1. Operasional Variabel

\begin{tabular}{|c|c|c|}
\hline Variabel & Definisi & Indikator \\
\hline $\begin{array}{l}\text { Komunikasi antar } \\
\text { pribadi orangtua } \\
\text { dengan anak }(\mathrm{X} 1)\end{array}$ & $\begin{array}{l}\text { Komunikasi } \\
\text { interpersonal } \\
\text { (antarpribadi) adalah } \\
\text { suatu proses komunikasi } \\
\text { yang terjadi antara dua } \\
\text { orang atau lebih yang } \\
\text { berlangsung secara tatap } \\
\text { muka maupun tidak } \\
\text { tatap muka, komunikasi } \\
\text { interpersonal ini sangat } \\
\text { efektif dan dapat } \\
\text { langsung di mengerti } \\
\text { dan diketahui respon } \\
\text { dari komunikan }\end{array}$ & $\begin{array}{l}\text { Empati (Empathy) } \\
\text { Keterbukaan (Oppenness) } \\
\text { Dukungan (Supportiveness) } \\
\text { Kesamaan (Equality) } \\
\text { Kepositifan (Positiveness) }\end{array}$ \\
\hline \multirow{4}{*}{ Perilaku seks (Y) } & $\begin{array}{l}\text { pengetahuan adalah hasil } \\
\text { yang didapatkan atau hasil } \\
\text { yang diketahui dari } \\
\text { penginderaan yang } \\
\text { dimiliki seseorang seperti } \\
\text { penglihatan, penciuman, } \\
\text { pendengaran } \\
\text { sebagainya }\end{array}$ & $\begin{array}{l}\text { Pengetahuan tentang } \\
\text { kesalahan dan penyimpangan } \\
\text { seksual agar individu dapat } \\
\text { menjaga diri dan melawan } \\
\text { eksploitasi yang dapat } \\
\text { mengganggu kesehatan fisik } \\
\text { dan mental } \\
\text { Pengertian dan kondisi yang } \\
\text { dapat membuat individu } \\
\text { melakukan aktivitas seksual } \\
\text { Membentuk sikap dan } \\
\text { memberikan pengertian } \\
\text { terhadap seks dan semua } \\
\text { manifestasi yang bervariasi } \\
\text { Bersentuhan (touching) }\end{array}$ \\
\hline & \multirow{3}{*}{$\begin{array}{l}\text { Perilaku seks adalah } \\
\text { segala tingkah laku yang } \\
\text { didorong oleh hasrat } \\
\text { seksual, baik dengan } \\
\text { lawan jenisnya maupun } \\
\text { dengan sesama jenis }\end{array}$} & Berciuman (kissing) \\
\hline & & Bercumbu (petting), \\
\hline & & Berhubungan badan (coitus) \\
\hline
\end{tabular}

Teknik analisis data pada penelitian ini menggunakan analisis regresi, uji validitas-reliabilitas, serta uji asumsi klasik (yang meliputi uji normalitas, heteroskedastisitas dan uji multikolinearitas). 


\section{Hasil Temuan dan Diskusi}

Berikut ini adalah tabel hasil uji validitas pada penelitian ini:

Tabel 2. Hasil Uji Validitas Komunikasi Interpersonal

\begin{tabular}{lccc}
\hline Pertanyaan & r hitung & r tabel & Keterangan \\
\hline 1 & 0,461 & 0,195 & Valid \\
\hline 2 & 0,458 & 0,195 & Valid \\
\hline 3 & 0,432 & 0,195 & Valid \\
\hline 4 & 0,473 & 0,195 & Valid \\
\hline 5 & 0,313 & 0,195 & Valid \\
\hline 6 & 0,496 & 0,195 & Valid \\
\hline 7 & 0,534 & 0,195 & Valid \\
\hline 8 & 0,432 & 0,195 & Valid \\
\hline 9 & 0,534 & 0,195 & Valid \\
\hline 10 & 0,289 & 0,195 & Valid \\
\hline
\end{tabular}

Tabel 3. Hasil Uji Validitas Pengetahuan Seks

\begin{tabular}{|c|c|c|c|}
\hline Pertanyaan & r hitung & $\mathrm{r}$ tabel & Keterangan \\
\hline 1 & 0,771 & 0,195 & Valid \\
\hline 2 & 0,543 & 0,195 & Valid \\
\hline 3 & 0,689 & 0,195 & Valid \\
\hline 4 & 0,605 & 0,195 & Valid \\
\hline 5 & 0,771 & 0,195 & Valid \\
\hline 6 & 0,474 & 0,195 & Valid \\
\hline
\end{tabular}

Tabel 4. Hasil Uji Validitas Perilaku Seks

\begin{tabular}{lccc}
\hline Pertanyaan & r hitung & r tabel & Keterangan \\
\hline 1 & 0,514 & 0,195 & Valid \\
\hline 2 & 0,887 & 0,195 & Valid \\
\hline 3 & 0,551 & 0,195 & Valid \\
\hline 4 & 0,306 & 0,195 & Valid \\
\hline 5 & 0,855 & 0,195 & Valid \\
\hline 6 & 0,514 & 0,195 & Valid \\
\hline 7 & 0,887 & 0,195 & Valid \\
\hline 8 & 0,831 & 0,195 & Valid \\
\hline
\end{tabular}

Berdasarkan pada hasil pengujian uji validitas dari ketiga variabel pada penelitian ini diketahui bahwa nilai $r$ hitung $>r$ tabel sehingga semua item pertanyaan untuk variabel komunikasi interpersonal, pengetahuan seks dan perilaku seks adalah valid. Kemudian dari hasil uji reliabilitas, diperoleh nilai Cronbach alpha untuk variabel X1 (komunikasi interpersonal) sebesar 0,774, untuk variabel pengetahuan seks (X2) didapat hasil CronbachAlpha sebesar 0,848 dan untuk variabel perilaku seks (Y) mendapatkannilai Cronbach Alpha sebesar 0,891. Karena nilai semua Cronbach Alpha diatas 0.6 maka ketiga variabel tersebut dikatakan reliabel 
One-Sample Kolmogorov-Smirnov Test

\begin{tabular}{|ll|r|}
\hline & & \multicolumn{1}{c|}{$\begin{array}{c}\text { Unstandardized } \\
\text { Residual }\end{array}$} \\
\hline $\mathrm{N}$ & Mean & 100 \\
Normal Parameters & $\mathbf{0}, 0$ & 0000000 \\
& Std. Deviation & 5,89279149 \\
Most Extreme Differences & Absolute &, 084 \\
& Positive & 042 \\
& Negative &,- 084 \\
Test Statistic & &, 084 \\
Asymp. Sig. (2-tailed) & &, $077^{\complement}$ \\
\hline
\end{tabular}

a. Test distribution is Normal.

b. Calculated from data.

c. Lilliefors Significance Correction.

Gambar 1. Uji Normalitas

Dari hasil pengujian SPSS untuk uji normalitas menggunakan Kolmogorov Smirnov nilai signifikansinya sebesar $0.77>0.05$ sehingga dengan demikian dapat dikatakan bahwa data pada penelitian ini terdistribusi normal. Untuk hasil uji multikolinearitas diperoleh hasil untuk Tolerance $0.949>0.1$ dan nilai VIF sebesar $1.054<10$ sehingga diketakan data telah bebas dari multikolinearitas. Sedangkan untuk uji heteroskedastisitas variabel independen yaitu komunikasi interpersonal nilai signifikansinya $0.748>0.05$, untuk variabel pengetahuan seks adalah $0,149>0.05$ sehingga dapat dikatakan bahwa databebas dari heteroskedastisitas. Untuk hasil pengujian regresi berganda dapat dilihat pada tabel berikut ini:

\begin{tabular}{|c|c|c|c|c|c|c|}
\hline \multirow[b]{2}{*}{ Mode } & & \multicolumn{2}{|c|}{ Unstandardized Coefficients } & \multirow{2}{*}{$\begin{array}{c}\text { Standardized } \\
\text { Coefficients }\end{array}$} & \multirow[b]{2}{*}{$t$} & \multirow[b]{2}{*}{ Siq. } \\
\hline & & $B$ & Std. Error & & & \\
\hline \multirow[t]{3}{*}{1} & (Constant) & 42,089 & 5,339 & & 7,884 &, 000 \\
\hline & Komunikasilnterpersonal & -274 &, 138 & -191 & $-1,991$ &, 049 \\
\hline & PendidikanSeks & -265 & 086 & -295 & $-3,074$ & .003 \\
\hline
\end{tabular}

Gambar 2. Regresi Linear Berganda $\mathrm{Y}=42,089-0,274 \mathrm{X} 1-0,265 \mathrm{X} 2+\mathrm{e}$

Hipotesis pertama pada penelitian ini adalah komunikasi interpersonal berpengaruh pada perilaku seks. Berdasarkan tabel tersebut diperoleh nilai signifikansi $\mathrm{t}$ untuk variabel komunikasi interpersonal sebesar 0,049 yang nilainya $<0,05$ dengan nilai koefisien $-0,274$.

Artinya komunikasi interpersonal berpengaruh negatif terhadap perilaku seks. Jadi hipotesis pertama diterima. Hipotesis kedua yang terdapat pada penelitian ini adalah pengetahuan seks berpengaruh terhadap perilaku seks. Diketahui pada tabel tersebut didapat nilai signifikansi t untuk variabel pengetahuan seks sebesar 0,003 yang nilainya $<0,05$ dengan nilaikoefisien -0,265. Artinya pengetahuan seks berpengaruh negatif terhadap perilaku seks. Jadi hipotesis kedua diterima. 


\section{Simpulan}

Berdasarkan dari hasil pembahasan tersebut, diketahui variabel komunikasi interpersonal berpengaruh negatif secara signifikan terhadap perilaku seks dan juga variabel pengetahuan seks berpengaruh negatif terhadap perilaku seks. Artinya semakin baik komunikasi interpersonal dengan orang tua, akan menurunkan perilaku seks dan semakin baik pengetahuan seks juga akan menurunkan perilaku seks. Sehingga secara keseluruhan dapat disimpulkan bahwa komunikasi interpersonal dan pengetahuan seks berpengaruh negatif terhadap perilaku seks.

\section{Ucapan Terima Kasih}

Penulis mengucapkan terimakasih banyak kepada Bapak Dr. Rezi. Erdiansyah, M.Si sebagai dosen pembimbing dan juga tim penguji yang telah meluangkan waktunya untuk membimbing penulis serta orangtua, teman-teman, responden dan juga sahabat penulis yang sangat membantu danmemberikan dukungan moral kepada penulis.

\section{Daftar Pustaka}

Effendy, Onong Uchjana. 2013. Ilmu, Teori dan Filsafat Komunikasi. Cetakan Ketiga. Bandung: PT. Citra Aditya Bakti.

Effendy, Uchjana Onong. 2014. Ilmu Komunikasi Teori dan Praktek. Bandung: PT. Remaja Rosdakarya.

Fathunaja, Anji . 2010. Reoriemtasi Pendidikan Seks Terhadap Anak Usia Remaja di Sekolah. .umm.ac.id. Yogyakarta.

Feriyani, B \& Fitri, A R. 2011. Perilaku Seksual Pranikah Ditinjau dari Intensitas Cinta dan Sikap terhadap Pornografi pada Dewasa Awal. Jurnal Psikologi. 7, 2, 119152.

Hoskins, J. A. 2014. Word of Mouth Research: Principles and Applications. Journal of Advertising, 47(4), 398-411. Retrieved from Springer Journal Database.

Ghozali, I. 2016. Analisis Multivariate dengan Program SPSS. Semarang: Undip.

Sekaran, B. 2012. Research Methods for Business: A skill Building Approach. New York: John Wiley \& Sons

Sugiyono, 2017. Metode Penelitian Bisnis. Bandung: CV Alfabeta. 